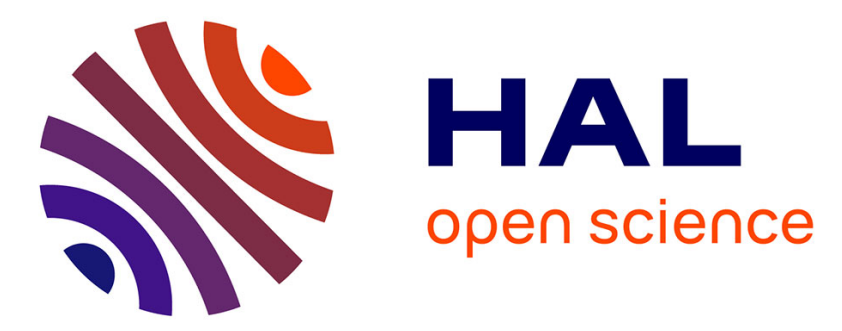

\title{
Bilayer Intumescent Paint Metal Laminates: A Novel Design for a High-Performance Fire Barrier
}

Laura Geoffroy, Fabienne Samyn, Maude Jimenez, Serge Bourbigot

\section{To cite this version:}

Laura Geoffroy, Fabienne Samyn, Maude Jimenez, Serge Bourbigot. Bilayer Intumescent Paint Metal Laminates: A Novel Design for a High-Performance Fire Barrier. Industrial and engineering chemistry research, 2020, 59 (7), pp.2988-2997. 10.1021/acs.iecr.9b06345 . hal-02611650

\section{HAL Id: hal-02611650 \\ https://hal.univ-lille.fr/hal-02611650}

Submitted on 18 May 2020

HAL is a multi-disciplinary open access archive for the deposit and dissemination of scientific research documents, whether they are published or not. The documents may come from teaching and research institutions in France or abroad, or from public or private research centers.
L'archive ouverte pluridisciplinaire HAL, est destinée au dépôt et à la diffusion de documents scientifiques de niveau recherche, publiés ou non, émanant des établissements d'enseignement et de recherche français ou étrangers, des laboratoires publics ou privés. 


\title{
Bi-layer intumescent paint metal laminate: a novel design for a high performance fire barrier
}

\author{
Laura GEOFFROY ${ }^{1}$, Fabienne SAMYN ${ }^{1}$, Maude JIMENEZ ${ }^{1}$, Serge BOURBIGOT ${ }^{*}$ \\ ${ }^{1}$ Univ. Lille, CNRS, ENSCL, UMR 8207, Unité Matériaux et Transformations (UMET), F-59000 Lille, France \\ laura.geoffroy@univ-lille.fr (L.G.), fabienne.samyn@univ-lille.fr (F.S.), maude.jimenez@univ-lille.fr (M.J.) \\ *corresponding author: serge.bourbigot@univ-lille.fr (S.B.); Phone: +33 (0)3 20434888
}

Keywords: Intumescent Polymer Metal Laminates, Delamination, Intumescent coating, Fire protection performances

\begin{abstract}
:
Intumescent paints are efficient fire barriers that rely on complex formulations of binder, flame retardants, synergists, fibers and minerals. Improvement of their performances through the formulation optimization is not simple. As an alternative, their recently use to form "intumescent polymer metal laminate", i.e. successive thin layers of aluminum foils and intumescent coatings has been shown to be promising (especially at the beginning of the fire testing) but it still shows limitations due to the processing and the low-thickness used that limits their efficiency. In this work, new fire barriers combining the use of two different intumescent paints (to mix their benefits) and a metal laminate structure have been evaluated. Different bilayer designs have been considered for the protection of steel. These bilayers are composed of the overlay of two intumescent coatings deposited or not on an aluminum foil. Cross-sections of the prepared materials were observed using optical microscopy. Then, all of samples were exposed to fire in a very high temperature environment (heat flux equal at $116 \mathrm{~kW} / \mathrm{m}^{2}$ ) using a burn-through test. The design with two aluminum foils and the overlay of both intumescent coatings reveals an efficient fire protection at the beginning of the test, and a stabilization at a low temperature after $30 \mathrm{~min}$ fire exposure. The fire protection performance of this design exhibits much higher performance than that of conventional intumescent coating of similar thickness. Tests stopped after different exposure time, cross-section of the residue observation, expansion measurement and pull-off tests were carried out to clarify the mechanism of action. This paper reveals a new way of thinking, and highlights that working on the design instead of changing the formulation of the intumescent paint allows to reach an efficient fire resistant barrier.
\end{abstract}




\section{Introduction}

In many fields, the demand for material which can resist to fire is in constant increase. To create such fire resistant materials, different ways can be considered.

A well-known approach consists in applying an intumescent coating on a substrate as a protective layer. Such coating is generally at least composed of a swelling agent, a carbon and an acid source [1 - 6]. When exposed to fire, the decomposition of these ingredients leads to the formation of an expanded porous insulating carbon barrier, commonly named "char". This porous residue prevents heat and mass transfers, thus protecting the substrate. The achieved level of performance greatly depends on the coatings used. Some of them provide quickly a high efficiency which only lasts for a short period, while others are less efficient at the beginning but then provide longer fire protection [6], [7].

Another approach consists in using Polymer Metal Laminates (PML) [9 - 13], inspired by Glass Laminate Aluminum Reinforced Epoxy (GLARE) which is a fiber metal laminate (a hybrid material) composed of several very thin layers of metal (usually aluminum) interspersed with layers of glass-fiber bonded with an epoxy matrix [14]. Thus, composed of alternating aluminum foils and thin epoxy resin layers [15], PML is a type of fire barrier which improves the fire performance thanks to the delamination of the structure. Indeed, under fire exposure, the epoxy resin decomposes, evolving gases which create a delamination. This delamination effectively decreases the heat conductivity of the material, reducing heat transfer in the materials (creation of an additional thermal resistance). The number of plies of the protection influences the overall performances of the fire barrier. In addition to fire protection, such laminated layer also contributes to improve the mechanical failure time of the substrate.

Recently, a combination of the two previously presented approaches has been proposed to combine both modes of action. Intumescent Polymer Metal Laminates (IPML) were thus developed by replacing the epoxy of PML by an intumescent paint between the aluminum foils [16]. It was demonstrated that, when glued on steel substrate, a ten plies IPML enables a drastic reduction of the temperature rise at the beginning of the fire test for a system based on chemical intumescence. Indeed, due to the delamination and the small residue formation between aluminum foils, the carbonization and thus the heat diffusion were delayed. Unfortunately, after $15 \mathrm{~min}$ of fire exposure, the temperature reaches the same value or is higher than the temperature measured for a sample simply coated with an intumescent coating layer. If 
carbonization is observed between aluminum foils, there is however no intumescence, most probably because of the too thin paint layer used between the aluminum foils.

In this context, this paper aims at designing new IPML inspired designs presenting high thermal insulating performances. Our strategy to reach this goal is to take advantage of the use of two intumescent paints targeting different fire scenarios, applied at higher thicknesses than in the IPML system and to benefit from the use of metal foils to also initiate delamination. Bilayer paint structures are proposed instead of the 10 layers of IPML, and a metal foil is placed at the interface between the two paints, and/or between the paint and the substrate (Figure 1). In the last case, the metal foil is glued on the substrate (Figure 1). After a characterization of these new fire barrier designs, their fire protection performances were evaluated and compared to reference materials, i.e. the neat intumescent coatings applied on steel plate, with the same global mass and thickness. Tests stopped after different exposure time, visual residue observations, expansion measurements and pull-off tests were carried out to investigate the mechanism of action.

\section{Materials and methods}

\section{Materials}

100x100x3 mm $\mathrm{mm}^{3}$ steel plates (grade XC38, Tartaix, Paris, France) were used as substrate. All of the plates were sandblasted (Normfinish, Jean Brel SA, Stains, France) to improve the coating adhesion, using a white aluminum oxide (Guyson, Chambly, France) (particle size around $355-500 \mu \mathrm{m}$ ), at a 5 bars pressure. Acetone (VWR, Radnor, Pennsylania, United States), was used to clean substrates prior to use. $30 \mu \mathrm{m}$ thick aluminum foils (Carl Roth, Karlsruhe, Germany) with $99 \%$ of purity were applied to elaborate bilayer metal laminate. Two intumescent coatings hereafter called A and B (proprietary formulation) were studied. Coatings $\mathrm{A}$ and $\mathrm{B}$ are commercial epoxy and acrylic based paints respectively containing conventional fire retardants (bi and mono-component, respectively). These two coatings were elaborated to be able to protect a substrate according to the UL 1709 and ISO 834 standards, and have a bubbling expansion when they are exposed to fire. Based on previous results, fully described in paper [16], these coatings were chosen because they revealed an efficient fire protection property in IPML design, especially at the beginning of the fire exposure. 


\section{Samples elaboration process}

Figure 1 presents the bilayer metal laminate process and the eleven samples prepared in this work. The name of the sample indicates its composition from the substrate to the top layer ( $\mathrm{S}$ for steel, A and B for paint type, Al for the aluminum foil). Bilayer Metal Laminate structures processing is carried out in several steps (Figure1) and depends on the structure of the bilayer laminate. The global intumescent coating mass deposited on the substrate is kept constant and corresponds to $20 \mathrm{~g}$ (total mass around $260 \mathrm{~g}$ substrate included) in order to be able to compare the different designs.

For the first layer:

i) Aluminum foils are cut into $100 \times 100 \mathrm{~mm}^{2}$ squares.

ii) Aluminum foil is glued onto sandblasted steel plate using almost $1 \mathrm{~g}$ of an epoxy resin (DGEBA, purchased form Sigma-Aldrich, St louis, Missouri, United Stated, reference 31185) cross-linked with Diethylenetriamine, (purchased from Sigma-Aldrich, St louis, Missouri, United States, reference D93856) with a ratio of 100:11.7.

iii) Curing step is performed for $48 \mathrm{~h}$ at room temperature, to fix the first aluminum foil onto steel plate.

iv) A controlled mass of intumescent coatings (A or B, according to the system studied) is manually applied onto aluminum foil glued onto steel plate, using a film applicator.

For the second layer:

v) A second aluminum foil is added on top of the first paint layer.

vi) The system is cured for $24 \mathrm{~h}$ at room temperature.

vii) A second intumescent coating (A or B according to the system elaborated) is applied on the aluminum layer.

viii) Finally, for the whole system is cured for $48 \mathrm{~h}$ at room temperature. Therefore, using this process, different intumescent bilayer metal laminates were prepared with one or two aluminum foils and two layers of coating A and B (Figure 1).

It is important to notice that, according to the system studied, some steps could be removed, as illustrated in Figure 1. Indeed, if no aluminum foil is put between the substrate and the first coating as $\mathrm{S}-\mathrm{A}+\mathrm{AlB}$ or $\mathrm{S}-\mathrm{B}+\mathrm{AlA}$, steps ii) and iii) are suppressed and coating is directly applied on the substrate according to step iv). 

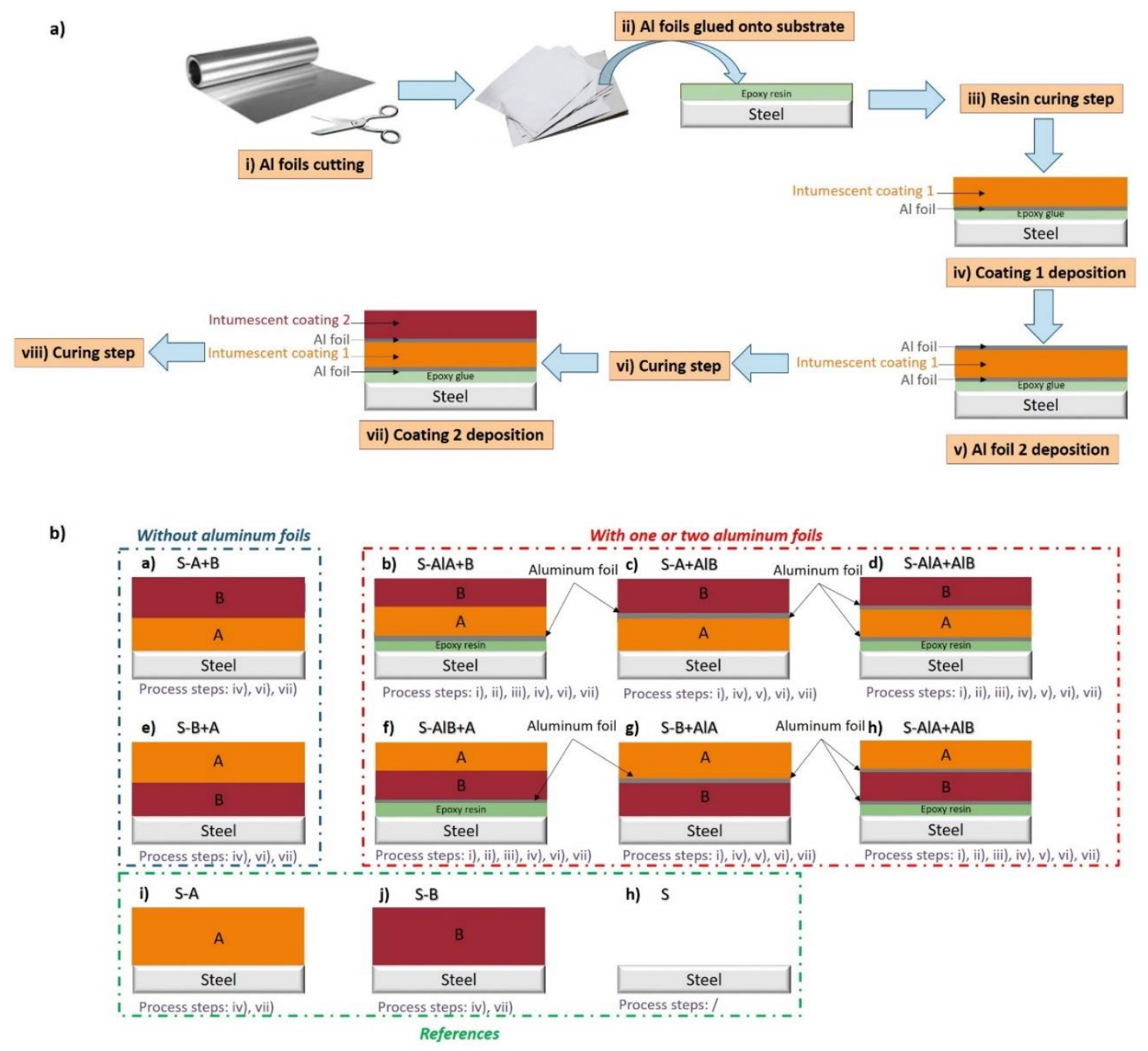

Figure 1. Intumescent bilayer metal laminate: a) Elaboration process, b) Samples studied.

To see if the addition of the metallic layers is efficient, some additional samples were prepared, namely S-A, S-B, S A+B and S-B+A, which were taken as reference. In that case, steel plates were covered using a film applicator, with coating A (S-A), or coating B (S-B), or both (S-A+B and $\mathrm{S}-\mathrm{B}+\mathrm{A}$ : with a $24 \mathrm{~h}$ curing step at room temperature between the first and the second intumescent coating deposition) (Figure 1). All paints were cured for $48 \mathrm{~h}$ at room temperature before fire testing. All samples were prepared in triplicate to check repeatability of results.

\section{Fire testing}

The reference (S-A, S-B, S-A+B and S-B+A) and metal laminated bilayer samples (S-AlA+B, $\mathrm{S}-\mathrm{AlB}+\mathrm{A}, \mathrm{S}-\mathrm{A}+\mathrm{AlB}, \mathrm{S}-\mathrm{B}+\mathrm{AlA}, \mathrm{S}-\mathrm{AlA}+\mathrm{AlB}, \mathrm{S}-\mathrm{AlB}+\mathrm{AlA}$ ) were tested to fire using a smallscale burn through test fully described in paper [17] and presented in figure 2 . The sample to be tested is placed between two $10 \mathrm{~mm}$ thick insulating Calsil panels (FINAL Advanced Materials), and fixed using screws. Flame calibration is firstly done for 5 min (Figure 2 a)). Samples are then directly subjected to the flame of a propane burner torch $\left(\sim 1100{ }^{\circ} \mathrm{C}\right.$ 
corresponding to a $116 \mathrm{~kW} / \mathrm{m}^{2}$ heat flux) for $30 \mathrm{~min}$ (Figure $2 \mathrm{~b}$ ). To compare the resistance to fire of the designed bilayers to the reference coating, temperature versus time is measured using a K-type thermocouple welded in the center of the backside of the steel plate. Data are recorded using an Agilent 34970A data logger. Moreover, the weight and thickness (using a ruler placed vertically) of all samples are measured before and after the torch test to calculate mass loss and intumescent expansion, respectively.

a)

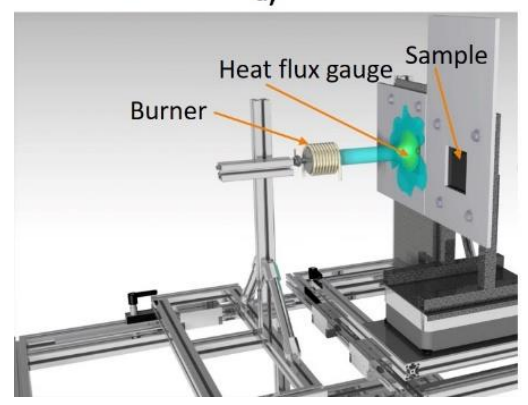

Figure 2. Burn-through test a) calibration, b) fire testing.

\section{Characterizations}

\subsection{Sample morphology}

Cross sections of the samples are embedded into an epoxy resin, which is then cured for $48 \mathrm{~h}$ at room temperature and finally polished (up to $0.25 \mu \mathrm{m}$ ) using silicon carbide disks (ESCIL, Chassieu, France). It is important to notice that all observations were done without substrate (steel plate), due to the difficulty to cut it and then embed it into epoxy resin.

Cross-section observations of each studied sample were carried out before fire exposure using an optical microscope VHX-1000 HDR (High Dynamic Range, Keyence, Osaka, Japan). After fire testing, residues were cut in cross-section using a thin cutter blade. The possible delamination of the coating was then observed visually.

\subsection{Expansion measurement}

The thicknesses of the samples before ( $\mathrm{e}$ before) and after $\mathrm{x}$ min of fire exposure ( $\mathrm{e}_{\text {after } \mathrm{x}}$ ) were measured using a numerical caliper and a thickness gauge. The expansion $(\mathrm{E})$ is calculated as the ratio between the thicknesses after and before fire testing $\left(\mathrm{E}=\left(\mathrm{e}_{\mathrm{after}} \mathrm{x}-\mathrm{e}_{\text {before }}\right) / \mathrm{e}\right.$ before $)$.

\subsection{Pull-off test}

Adhesion tests of S-A, S-AlA were carried out using a pull-off test (Erichsen, Hemer, Germany) (Figure 3 e)). This test procedure is divided into four main steps. First, the bilayer is cut down 
to the substrate in a circle which is the size of the dolly used for the test (Figure $3 \mathrm{a}$ )). Then, the dolly is glued on the delimited area using a cyanoacrylate adhesive (Henkel, Düsseldorf, Germany) dried for 48 hours at room temperature (Figure $3 \mathrm{~b}$ )). The dolly is tightened up on the loading gauge (Figure $3 \mathrm{c}$ )). The gauge is reset before applying the load. Finally, the load is manually smoothly increased using a crank handle. The pull-off force is measured when failure occurs using a manometer (Figure $3 \mathrm{~d}$ )).
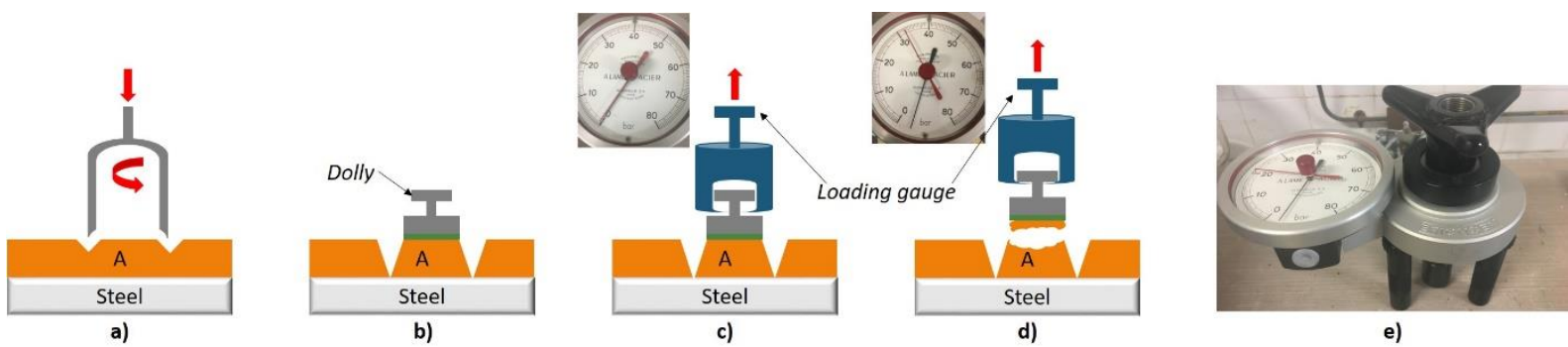

Figure 3. Description of pull-off test.

\section{Results and discussion}

\section{Intumescent bilayer metal laminate characterizations before fire test}

The bilayers morphology of the materials has been characterized using optical microscopy. Cross section pictures of the different coatings (without substrate) are gathered in Figure 4. It should be noticed that, for cross section analyses, the coatings were not applied on steel substrates. This explains why the cross sections of $\mathrm{S}-\mathrm{A}+\mathrm{B}$ and $\mathrm{S}-\mathrm{B}+\mathrm{A}$ are not presented, but it is assumed that their aspect is similar to the cross sections of $\mathrm{S}-\mathrm{AlA}+\mathrm{B}$ and $\mathrm{S}-\mathrm{AlB}+\mathrm{A}$, respectively, as the only difference is the presence of the aluminum foil. From these cross section pictures (Figure 4), it is noticed that the adhesion between layers is homogeneous. In addition to this, the thickness of each layer has been estimated, and average values of each layer and total sample thicknesses and masses are reported in Table 1. It can be observed that when $10 \mathrm{~g}$ of coating is deposited, thicknesses of around $700 \mu \mathrm{m}$ and $600 \mu \mathrm{m}$ for coatings $\mathrm{A}$ and $\mathrm{B}$, respectively. Some bubbles are observed in paint layers (which correspond to the removal of large particles during polishing), but not at the interfaces coating/coating or coating/aluminum (Figure 4). All samples look homogeneous (Table 1), and exhibit similar thicknesses (between 4.7 and $4.9 \mathrm{~mm}$ ) and total coating masses (around $15.8 \mathrm{~g}$ ). The relative gaps of $4 \%$ for the thickness and $6 \%$ for the total mass are indeed considered as negligible. 
a) S-A

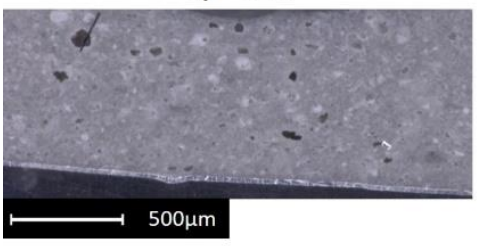

c) S-AIA+B

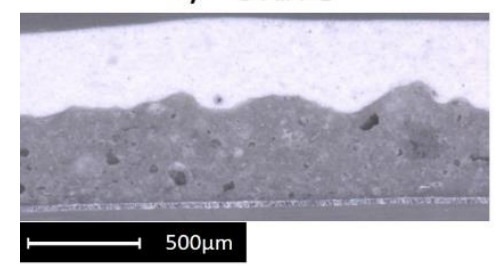

f) $S-A I B+A$

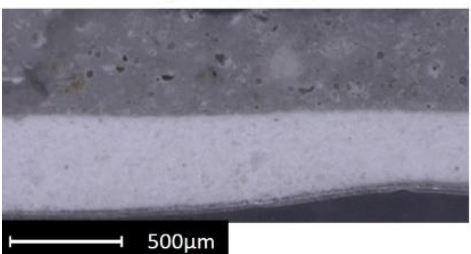

b) S-B

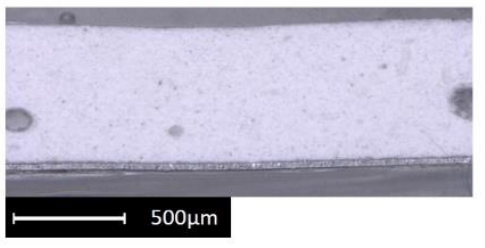

d) S-A+AlB

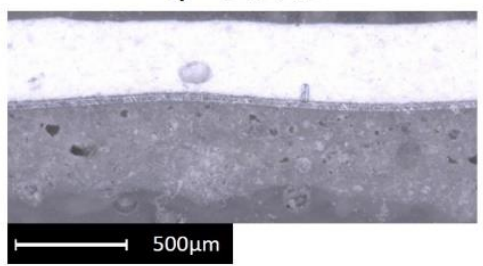

g) $S-B+A l A$

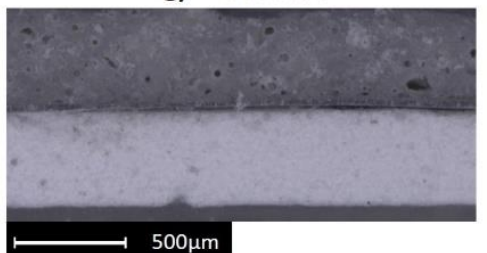

e) $S-A \mid A+A I B$

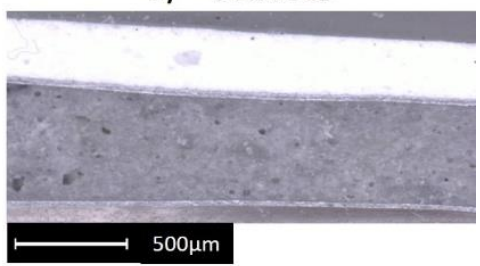

h) $\mathrm{S}-\mathrm{AlB}+\mathrm{AlA}$

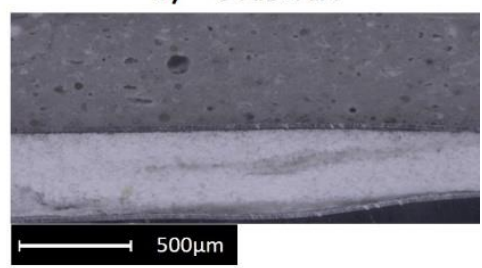

Figure 4. Optical microscopy observation in cross-section of the studied samples

Table 1. Quantitative characterization of each sample studied.

\begin{tabular}{ccccccc}
\hline Samples & $\begin{array}{c}\text { Mass of } \\
\text { coating A } \\
(\mathbf{g})\end{array}$ & $\begin{array}{c}\text { Mass of } \\
\text { coating B } \\
\mathbf{( g )}\end{array}$ & $\begin{array}{c}\text { Total } \\
\text { mass }(\mathrm{g})\end{array}$ & $\begin{array}{c}\text { A } \\
\text { thickness } \\
\text { layer } \\
(\mu \mathrm{\mu m})\end{array}$ & $\begin{array}{c}\text { B } \\
\text { thickness } \\
\text { layer }(\mu \mathrm{m})\end{array}$ & $\begin{array}{c}\text { Total } \\
\text { thickness } \\
(\mathbf{m m})\end{array}$ \\
\hline S-A & $19.5 \pm 0.6$ & & $256.5 \pm 0.4$ & $\sim 1300$ & & $4.85 \pm 0.07$ \\
\hline S-B & & $19.6 \pm 0.1$ & $260.4 \pm 0.2$ & & $\sim 1200$ & $4.7 \pm 0$ \\
\hline S-A+B & $10.2 \pm 0.1$ & $10.23 \pm 0.03$ & $251.2 \pm 0.1$ & $\sim 700$ & $\sim 600$ & $4.8 \pm 0$ \\
\hline S-A+AlB & $10.2 \pm 0.1$ & $10.23 \pm 0.03$ & $251.2 \pm 0.5$ & $\sim 670$ & $\sim 620$ & $4.8 \pm 0.01$ \\
\hline S-AlA+B & $10.21 \pm 0.04$ & $10.2 \pm 0.2$ & $258 \pm 1$ & $\sim 700$ & $\sim 600$ & $4.7 \pm 0$ \\
\hline S-AlA+AlB & $9.96 \pm 0.02$ & $10.4 \pm 0.2$ & $257 \pm 3$ & $\sim 700$ & $\sim 620$ & $4.9 \pm 0.1$ \\
\hline S-B+A & $10.88 \pm 0.03$ & $11.36 \pm 0.01$ & $255 \pm 2$ & $\sim 780$ & $\sim 700$ & $4.7 \pm 0$ \\
\hline S-B+AlA & $10.0 \pm 0.7$ & $9.91 \pm 0.04$ & $266 \pm 3$ & $\sim 670$ & $\sim 620$ & $4.8 \pm 0$ \\
\hline S-AlB+A & $10.6 \pm 0.5$ & $10.6 \pm 0.3$ & $267 \pm 2$ & $\sim 780$ & $\sim 700$ & $4.9 \pm 0.1$ \\
\hline S-AlB+AlA & $10.2 \pm 0.5$ & $10.0 \pm 0.5$ & $254 \pm 1$ & $\sim 700$ & $\sim 600$ & $4.8 \pm 0.1$ \\
\hline
\end{tabular}




\section{Fire behavior}

Fire protection performance of steel coated with intumescent coatings (A, B and the overlay of $\mathrm{A}+\mathrm{B}$ and $\mathrm{B}+\mathrm{A}$ ) were compared to the raw steel plate. Figure 5 a) shows the evolution of the temperature versus time at the backside of the systems, and Table 2 gathers temperatures reached at the end of fire test (steady state) and reports the slope of the curves at different time intervals of fire test. The temperature at the backside of the raw steel plate dramatically increases from the beginning of the fire test (with $300^{\circ} \mathrm{C} / \mathrm{min}$ as a slope) and reaches its steady state temperature at $620^{\circ} \mathrm{C}$ after $10 \mathrm{~min}$ fire test (Table 2). For the steel plate coated with intumescent paint $\mathrm{A}$, the temperature increases until $4 \mathrm{~min}$, with a slope $\left(102^{\circ} \mathrm{C} / \mathrm{min}\right), 66 \%$ lower than the slope of the reference at the beginning of the fire exposure. Then the slope of SA dramatically decreases and temperature reaches $345^{\circ} \mathrm{C}(44 \%$ lower than the temperature reached for the raw steel). For S-B, similar observations can be done: from the beginning of the fire test until $2 \mathrm{~min}$, the slope of S-B is 55\% lower than the slope of S (Table 2). Then, it decreases and temperature reaches a plateau at $270^{\circ} \mathrm{C}$. Both intumescent coatings thus protect steel versus fire, however coating B seems to show a better resistance to fire at the end of the test while coating $\mathrm{A}$ is more efficient at the beginning of the test (with a slope $24 \%$ lower than the slope of S-B). For this reason, the resistance to fire of the overlay of coatings A and B was evaluated ( $\mathrm{S}-\mathrm{A}+\mathrm{B}$ and $\mathrm{S}-\mathrm{B}+\mathrm{A})$, to try to combine both coatings advantages. $\mathrm{S}-\mathrm{A}+\mathrm{B}$ and $\mathrm{S}-\mathrm{B}+\mathrm{A}$ exhibits similar fire protection. From the beginning to 1 min fire test, the slopes of $\mathrm{S}-\mathrm{A}+\mathrm{B}$ and $\mathrm{S}-\mathrm{B}+\mathrm{A}$ are $68 \%, 25 \%$ and $2 \%$ lower than the slopes of S, S-B and S-A, respectively (Table 2). After 30 min fire test, the temperature reaches $320{ }^{\circ} \mathrm{C}(48 \%$ lower than temperature reached for $\mathrm{S}$ and $19 \%$ higher than temperature reached for S-B). Therefore, the temperature profiles of the simple overlay of coatings A and B do not allow to improve the fire protection performance. Other designs (bilayer metal laminates) were considered afterward to see the aluminum foil benefice in the system with an intumescent coating combination. 
a)
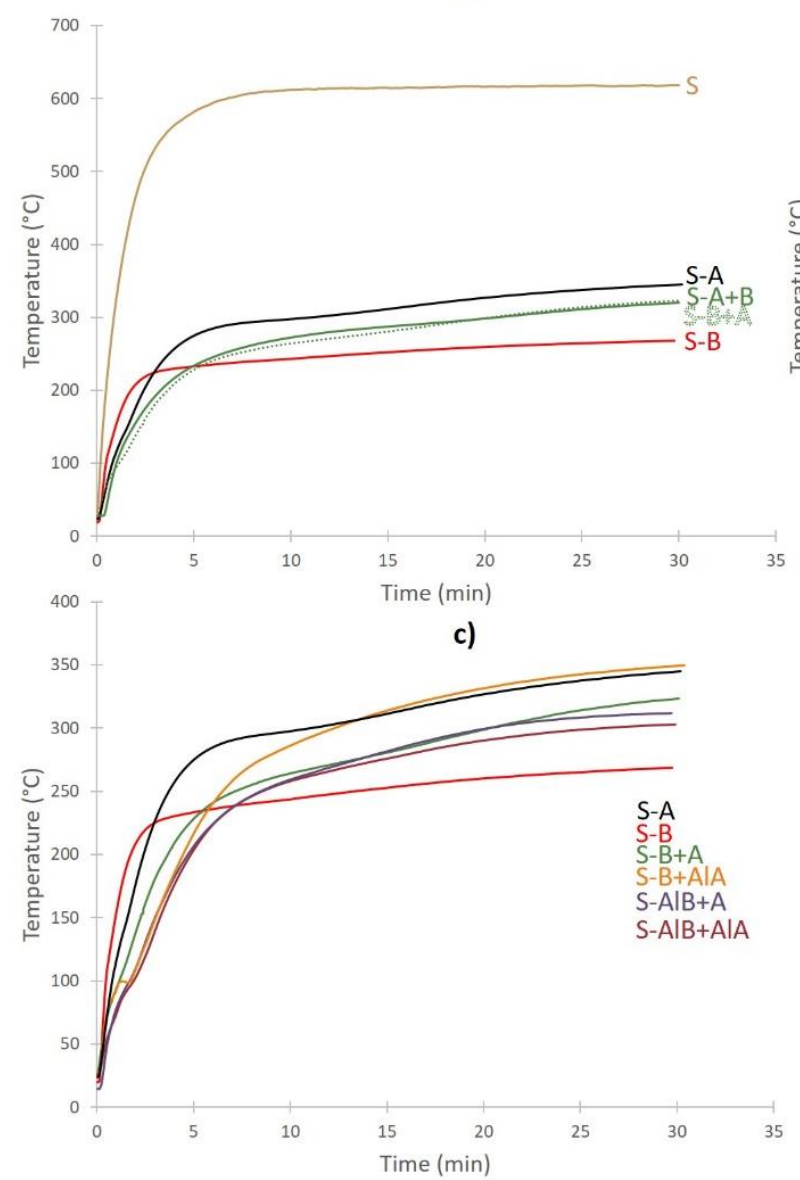

b)

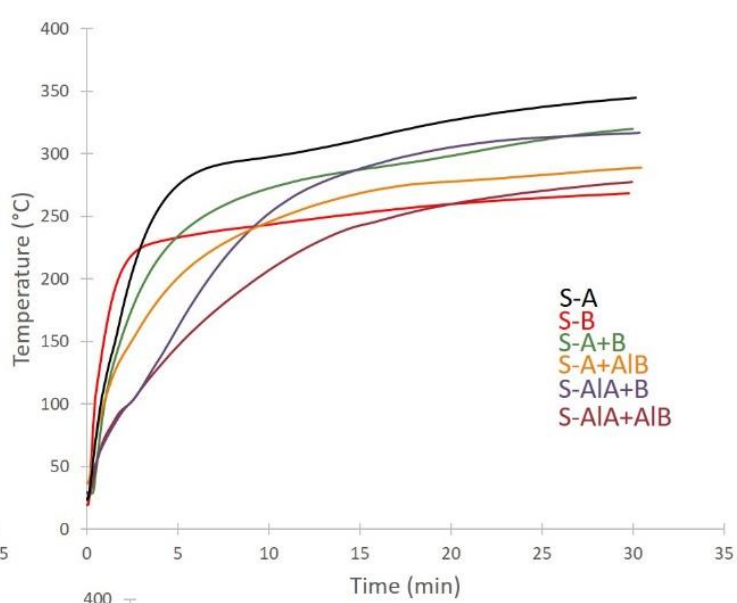

d)

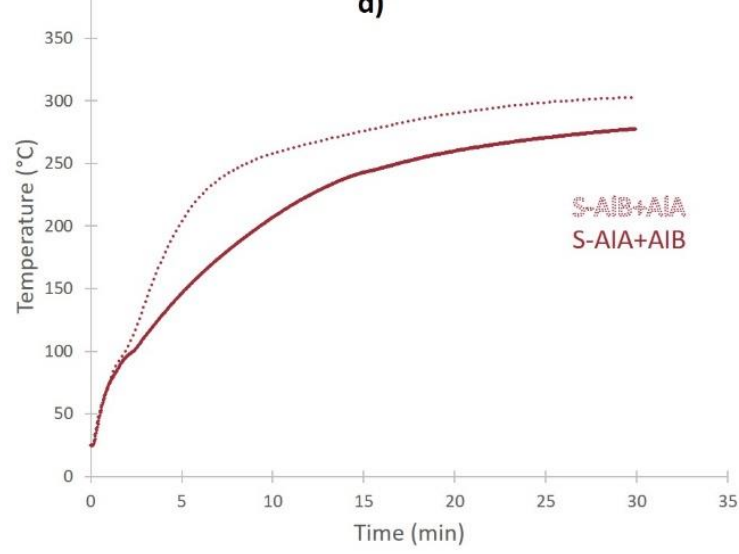

Figure 5. Fire protection performance comparison of each system studied (a) for the overlay A (steel side) and B (A side), b) for the overlay B (steel side) and A (B side), c) for the two best systems).

The fire performance of laminated samples $(\mathrm{S}-\mathrm{A}+\mathrm{AlB}, \mathrm{S}-\mathrm{B}+\mathrm{AlA}, \mathrm{S}-\mathrm{Al} \mathrm{A}+\mathrm{B}, \mathrm{S}-\mathrm{AlB}+\mathrm{A}, \mathrm{S}-$ $\mathrm{AlA}+\mathrm{AlB}, \mathrm{S}-\mathrm{AlB}+\mathrm{AlA}$ ) were then compared to those of samples simply coated with the paints (S-A, S-B, S-A+B and S-B+A). The resulting curves are gathered in Figure 5. Figure 5 b) shows temperature versus time curves for the bilayers with A the bottom layer (steel side) and B the top layer. On the contrary, in figure $5 \mathrm{c}$ ), B is the bottom layer and A the top layer. In both cases, better resistance to fire performance is obtained at the beginning of the test for the systems with aluminum foils and the designs with two aluminum foils (S-AlA+AlB and S$\mathrm{AlB}+\mathrm{AlA}$ ) show the best results. Moreover, the $\mathrm{S}-\mathrm{AlA}+\mathrm{AlB}$ design reveals better fire protection performance compared to S-AlB+AlA (Figure $5 \mathrm{~d}$ )).

In the case of the overlay B (bottom)/A (top), all systems with one or two aluminum foils exhibit almost the same fire behavior with a lower temperature rise from the beginning to $5 \mathrm{~min}$ of test compared to $\mathrm{S}-\mathrm{B}+\mathrm{A}$. But after $5 \mathrm{~min}$ fire exposure, no stabilization of the temperature is observed, and temperature still increases to reach between 270 and $350^{\circ} \mathrm{C}$ at the end of the test. The temperatures reached after 30 min fire exposure are similar to those obtained with $\mathrm{S}-\mathrm{A}+\mathrm{B}$ 
and S-A. These samples do not provide the same fire protection properties compared to S-B, particularly after 5 min of flame exposure. It is assumed that the expansion of coating B is modified and lower, because of coating A on the top, and the presence (for some systems) of aluminum foil. Figure 6 reveals the less expansion of coating B in the case of S-B+AlA (Figure 6 a)), which has a global expansion of 308\%, and S-A+AlB residues (Figure 6 b)), which has a global expansion of $602 \%$. Subsequently, S-A+B was selected as the reference for the beginning of the test due to its best fire protection performance, and S-B was chosen at the end of the fire test because this system retains the lowest temperature after $30 \mathrm{~min}$ fire exposure.

a)

S-B+AIA

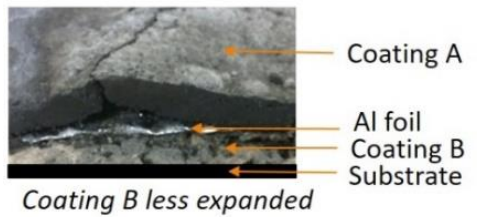

b)

S-A+AlB

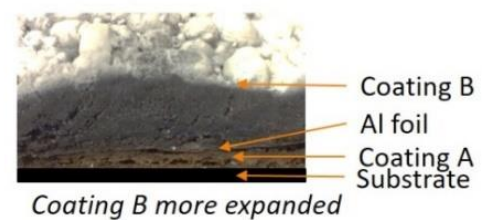

Figure 6. Comparison of coating B expansion between a) $S-B+A l A$ and b) $S-A+A l B$

Having the coating B in the top layer leads to more differentiated behaviors of the samples and better performances compared to samples with $\mathrm{B}$ in the bottom layer. Indeed, the final temperatures of the different designs are between 250 and $300^{\circ} \mathrm{C}$, consequently the systems remain at least as efficient as the $\mathrm{S}-\mathrm{A}+\mathrm{B}$ design. However, because of an additional fire resistance (which will describe in the next part), the increase of temperature during the fire testing, is better for the system with aluminum foils. For S-A+AlB a change of slope is observed at $1 \mathrm{~min}$, and a reduction of the slope by $27 \%$ is observed. Then, after $30 \mathrm{~min}$ fire test, the temperature reaches $290{ }^{\circ} \mathrm{C}, 20{ }^{\circ} \mathrm{C}$ higher than temperature reached for S-B (Table 2). Aluminum foil between $\mathrm{A}$ and $\mathrm{B}$ allows to delay the temperature diffusion in the system at the beginning of the test, but after 9 min of fire exposure, the benefit of the design is lost compared to $\mathrm{S}-\mathrm{B}$. For $\mathrm{S}-\mathrm{AlA}+\mathrm{B}$, at the beginning of the test, a lower slope reduced by $57 \%$ compared to the slope of $\mathrm{S}-\mathrm{A}+\mathrm{B}$, and an inflexion point at $2.5 \mathrm{~min}$, are observed, which improves the resistance to fire of the system. But similarly to $\mathrm{S}-\mathrm{A}+\mathrm{AlB}$, for longer time, higher than 9 min, the improvement is lost, leading to a maximum temperature of $316^{\circ} \mathrm{C}$ after $30 \mathrm{~min}$ fire test. For $\mathrm{S}-\mathrm{AlA}+\mathrm{AlB}$, an inflexion point is observed at almost $2.5 \mathrm{~min}$, with a slope reduction of $60 \%$ compared to $\mathrm{S}-\mathrm{A}+\mathrm{B}$. This system exhibits better resistance to fire performances than $\mathrm{S}-\mathrm{B}$ up to $20 \mathrm{~min}$. Indeed, $\mathrm{S}-\mathrm{AlA}+\mathrm{AlB}$ reaches $250^{\circ} \mathrm{C}$ after $17 \mathrm{~min}$ fire exposure compared to $13.5 \mathrm{~min}$ of fire test for S-B. At the end of the test, a temperature of $280^{\circ} \mathrm{C}$ is recorded which is only $10^{\circ} \mathrm{C}$ higher than the temperature of S-B. 
Table 2. Rates of change of temperature according to different times, and temperatures reach after 30 min fire exposure

\begin{tabular}{|c|c|c|c|c|c|c|c|c|c|c|}
\hline \multirow[t]{2}{*}{ Samples } & \multirow{2}{*}{$\begin{array}{l}\text { Rate of change of } \\
\text { Temperature } \\
\left({ }^{\circ} \mathrm{C} / \mathrm{min}\right): \\
\text { from } 0 \mathrm{~s} \text { to } 1 \mathrm{~min}\end{array}$} & \multicolumn{2}{|c|}{$\%$ reduction } & \multirow{2}{*}{$\begin{array}{l}\text { Rate of change } \\
\text { of Temperature } \\
\left.\text { ( }{ }^{\circ} \mathrm{C} / \mathrm{min}\right) \text { : } \\
\text { from } 1 \text { to } 2 \mathrm{~min}\end{array}$} & \multicolumn{2}{|c|}{$\%$ reduction } & \multirow{2}{*}{$\begin{array}{c}\text { Time to } \\
\text { reach } 250^{\circ} \mathrm{C} \\
\quad(\min )\end{array}$} & \multirow{2}{*}{$\begin{array}{l}\text { Temperature } \\
\text { after } 30 \mathrm{~min} \\
\text { fire test }\left({ }^{\circ} \mathrm{C}\right)\end{array}$} & \multicolumn{2}{|c|}{$\begin{array}{c}\text { \% Reduction of } \\
\text { Temperature } \\
\text { after } 30 \text { min fire } \\
\text { test }\end{array}$} \\
\hline & & $\begin{array}{c}\text { Against } \\
\text { S }\end{array}$ & $\begin{array}{c}\text { Against } \\
\mathrm{S}-\mathrm{A}+\mathrm{B}\end{array}$ & & $\begin{array}{c}\text { Against } \\
\text { S }\end{array}$ & $\begin{array}{c}\text { Against } \\
\text { S-A+B }\end{array}$ & & & $\begin{array}{c}\text { Against } \\
\text { S }\end{array}$ & $\begin{array}{c}\text { Against } \\
\text { S-B }\end{array}$ \\
\hline $\mathrm{S}$ & 300 & & & 129 & & & 0.7 & 620 & & \\
\hline S-A & 102 & $-66 \%$ & & 59 & $-54 \%$ & & 3.7 & 345 & $-44 \%$ & \\
\hline S-B & 134 & $-55 \%$ & & 48 & $-63 \%$ & & 13.5 & 270 & $-56 \%$ & \\
\hline S-B+A & 95 & $-68 \%$ & & 44 & $-66 \%$ & & 7 & 320 & $-48 \%$ & \\
\hline S-A+B & 100 & $-67 \%$ & & 45 & $-65 \%$ & & 6.5 & 320 & $-48 \%$ & $+19 \%$ \\
\hline S-AlA+B & 43 & & $-57 \%$ & 24 & & $-47 \%$ & 9.9 & 320 & & $+19 \%$ \\
\hline S-A+AlB & 73 & & $-27 \%$ & 34 & & $-24 \%$ & 10.8 & 290 & & $+7 \%$ \\
\hline S-AlA+AlB & 40 & & $-60 \%$ & 22 & & $-51 \%$ & 17 & 280 & & $+4 \%$ \\
\hline S-AlB+A & 76 & & $-24 \%$ & 31 & & $-31 \%$ & 8.5 & 312 & & $+16 \%$ \\
\hline S-B+AlA & 83 & & $-17 \%$ & & & & 6.5 & 345 & & $+28 \%$ \\
\hline S-AlB+AlA & 55 & & $-45 \%$ & 30 & & $-33 \%$ & 8.5 & 303 & & $+12 \%$ \\
\hline
\end{tabular}




\section{Mechanism investigation}

To understand the differences in term of fire performance between the laminated samples (S$\mathrm{A}+\mathrm{AlB}, \mathrm{S}-\mathrm{AlA}+\mathrm{B}, \mathrm{S}-\mathrm{Al} \mathrm{A}+\mathrm{AlB}$ ) and the references $\mathrm{S}-\mathrm{A}, \mathrm{S}-\mathrm{B}$ and $\mathrm{S}-\mathrm{A}+\mathrm{B}$, some additional experiments were done. Each sample was exposed to fire for different durations (40 s, $2 \mathrm{~min}$, $10 \mathrm{~min}$ and $30 \mathrm{~min}$ ). At each time, the cross-section of the residue was visually observed (Figure 8 and Figure 9), and the expansion was measured (Figure 7).

For sample without aluminum foils (S-A, S-B and S-A+B), coatings degrade during the fire exposure, a residue is formed, and no delamination is observed (Figure 8). S-A residue looks very dense and cohesive, with an expansion of $165 \%$ after 30 min fire test, as illustrated in Figure 7 and 8. In comparison, S-B residue is brittle with a high expansion of 983\% (Table 3, Figure 7 and 8), 6 times higher than that of S-A expansion. The residue obtained for $\mathrm{S}-\mathrm{A}+\mathrm{B}$ is dense and less expanded than S-B residue (twice lower). Figure 7 reports that S-A+AlB and S$\mathrm{AlA}+\mathrm{AlB}$ have almost the same expansion (around 600\%) over fire exposure time. Same observation was done for $\mathrm{S}-\mathrm{A}+\mathrm{B}$ and $\mathrm{S}-\mathrm{AlA}+\mathrm{B}$ expansion (around 350\%) (Table 3). Therefore, it is possible to consider that aluminum foil (glued onto steel plate) has no influence on the residue expansion, on the contrary to coating A which clearly influences expansion of the $\mathrm{B}$ paint and thus its fire protective properties.

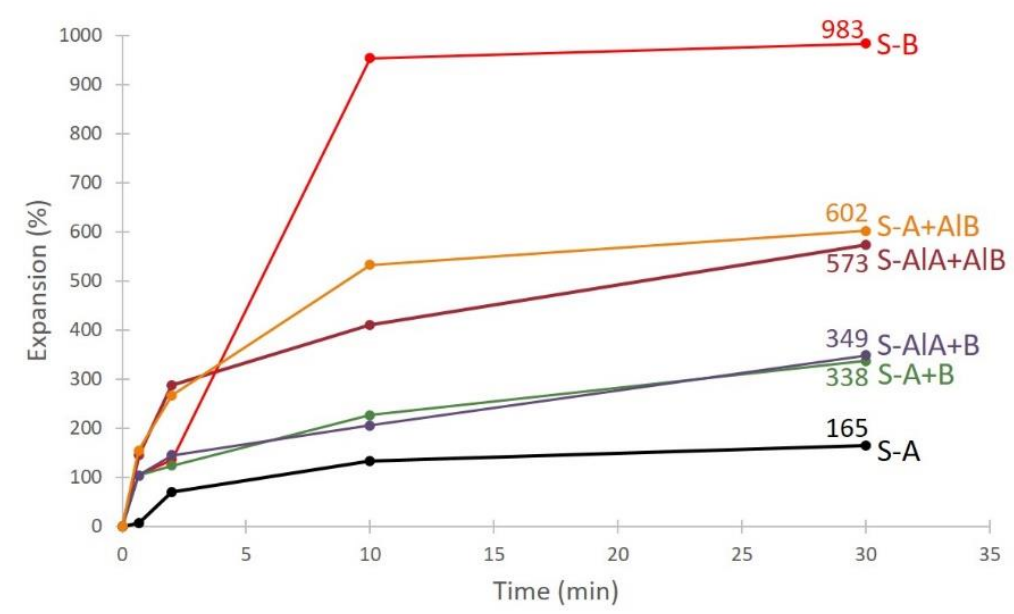

Figure 7. Expansion evolution versus time for each sample studied.

Table 3. Expansion values evolution versus time for each sample studied

\begin{tabular}{cccccc}
\hline \multirow{2}{*}{ Samples } & \multicolumn{5}{c}{ Expansion (\%) } \\
\cline { 2 - 6 } & $\mathbf{0}$ (min) & $\mathbf{4 0}(\mathrm{s})$ & $\mathbf{2}$ (min) & $\mathbf{1 0 ~ ( m i n )}$ & $\mathbf{3 0}$ (min) \\
\hline S-A & 0 & 6 & 70 & 134 & 165 \\
\hline
\end{tabular}




\begin{tabular}{cccccc}
\hline S-B & 0 & 104 & 137 & 954 & 983 \\
\hline S-A+B & 0 & 104 & 124 & 227 & 338 \\
\hline S-AlA+B & 0 & 104 & 145 & 206 & 349 \\
\hline S-A+AlB & 0 & 155 & 267 & 533 & 602 \\
\hline S-AlA+AlB & 0 & 145 & 288 & 410 & 573 \\
\hline
\end{tabular}

When aluminum foil is added in the systems, different behaviors occur (Figure 9): for S-AlA+B, at $40 \mathrm{~s}$, the residue starts to decompose to the top, coating A remains intact. At 2 min fire test, a delamination between coating and aluminum foil occurs (Figure $9 \mathrm{c}$ )). This delamination is maintained throughout the test up to 30 minutes of exposure to fire. $\mathrm{S}-\mathrm{AlA}+\mathrm{B}$ and $\mathrm{S}-\mathrm{A}+\mathrm{B}$ residues have the same aspect, except for the delamination observed in the case of S-AlA+B. For S-A+AlB, the B-residue on the top starts to form (contrary to coating A which seems apparently unaffected) and no delamination is observed at 2 min. However, a delamination between the aluminum foil and the coating A appears after 10 min of fire test (Figure $9 \mathrm{~b}$ )) and is maintained until $30 \mathrm{~min}$ of fire exposure. This delamination which occurs at different times ( 2 min for $\mathrm{S}-\mathrm{AlA}+\mathrm{B}$ and $10 \mathrm{~min}$ for $\mathrm{S}-\mathrm{A}+\mathrm{AlB}$ ) could explain the different temperature versus time curves obtained and illustrated in Figure 5 a). Indeed, the delamination at 2 min could cause the inflexion point observed at $2.5 \mathrm{~min}$ for $\mathrm{S}-\mathrm{AlA}+\mathrm{B}$ that is not observed for $\mathrm{S}-\mathrm{A}+\mathrm{AlB}$.

For $\mathrm{S}-\mathrm{AlA}+\mathrm{AlB}$, after $40 \mathrm{~s}$ fire exposure, coating $\mathrm{B}$ on the top starts to decompose. At 2 min, coating A starts to decompose, and two delaminations between (i) aluminum foil (glued onto steel plate) and coating A and (ii) coating A and aluminum foil (between coating A and coating B) occur (Figure 9 a)). These two delaminations remain until the end of the test, creating an additional thermal resistance, and could justify the better resistance to fire performance of $S$ $\mathrm{AlA}+\mathrm{AlB}$ compared to the other systems. 
a)

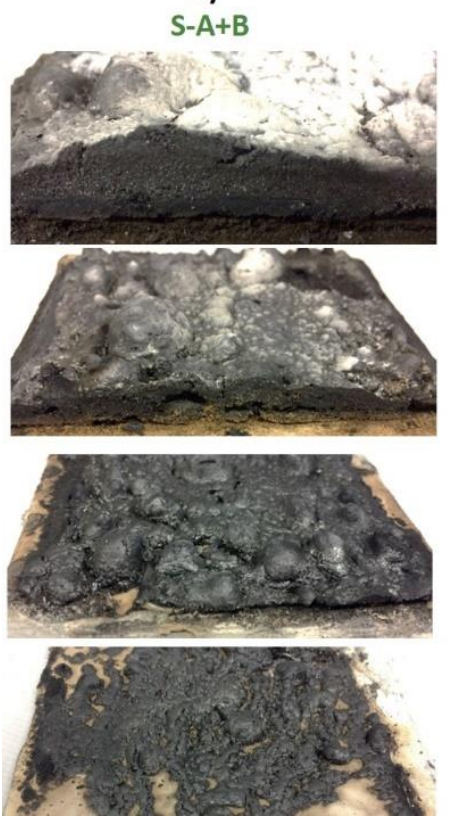

b)

Fire testing time S-A

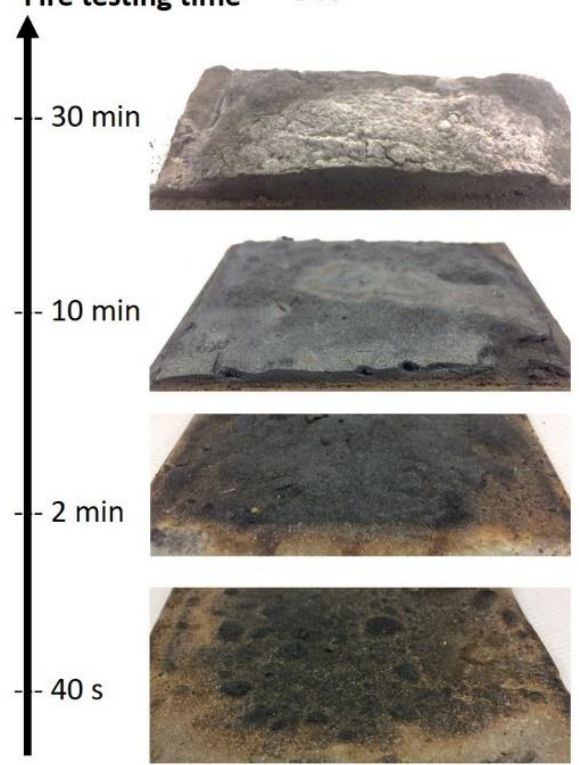

c)

Fire testing time S-B

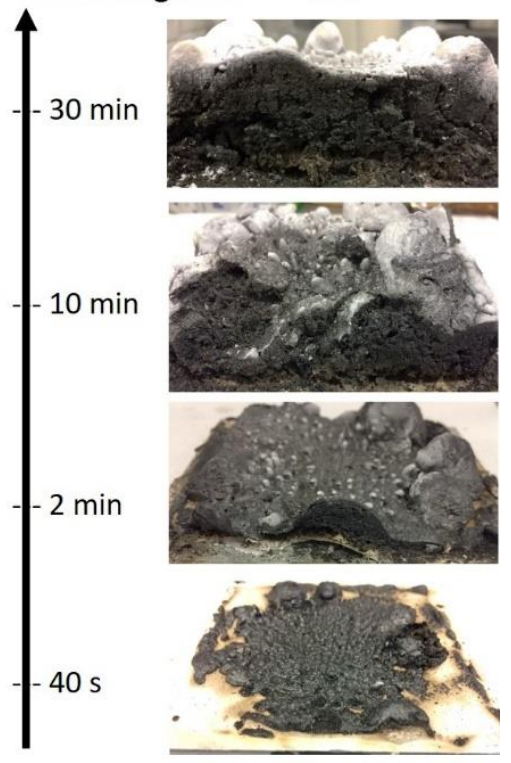

Figure 8. Fire tests stopped at different exposure times for the systems (a) $S-A+B, b) S-A, c) S-B$ ).

a)

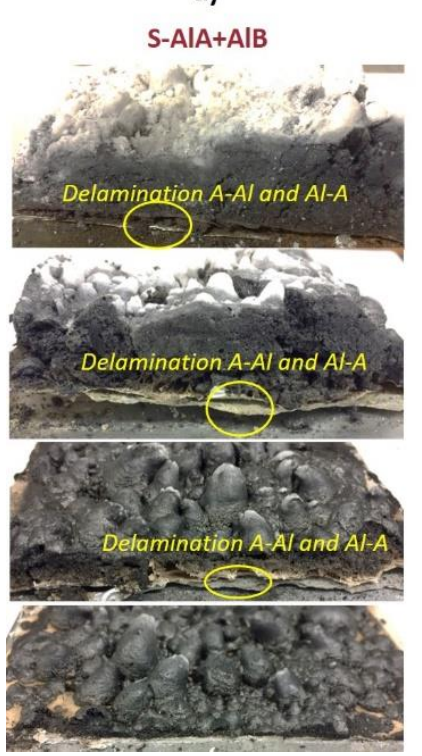

b)

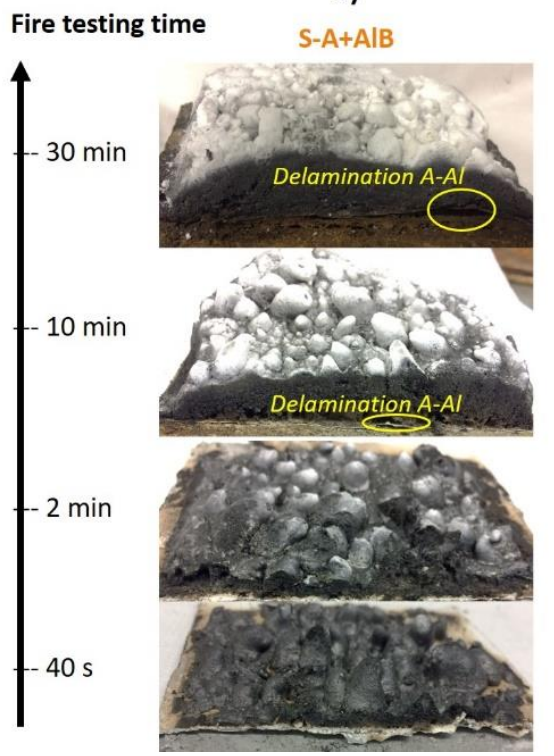

c)

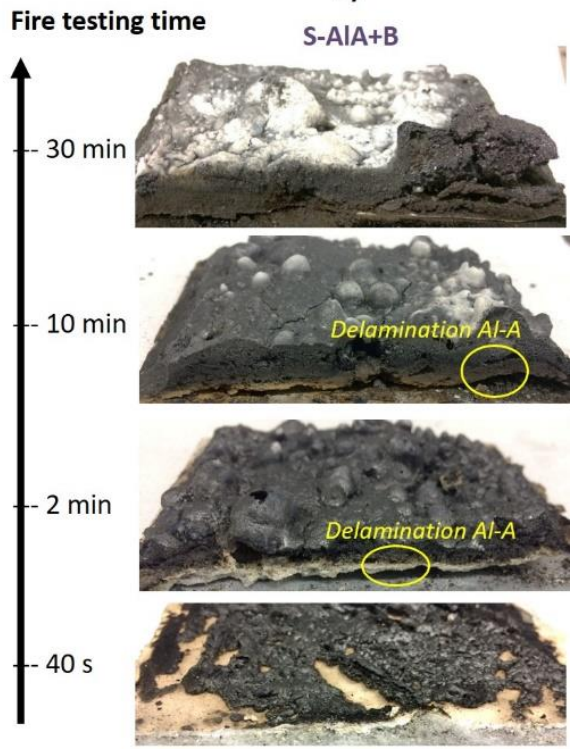

Figure 9. Fire tests stopped at different exposure times for the designs (a) $S$-AlA+AlB, b) $S-A+A l B, c$ ) $S-A l A+B)$.

Based on the previously presented analyses, Figure 10 summarizes the mechanisms of action of the fire barriers $\mathrm{S}-\mathrm{A}+\mathrm{B}, \mathrm{S}-\mathrm{AlA}+\mathrm{B}, \mathrm{S}-\mathrm{A}+\mathrm{AlB}, \mathrm{S}-\mathrm{AlA}+\mathrm{AlB}$. Two main conclusions can be drawn. On one hand, delamination only occurs when aluminum foils are used and preferentially at the interface with coating A. Indeed, no delamination is visible for $\mathrm{S}-\mathrm{A}+\mathrm{B}$ (Figure $10 \mathrm{~d}$ )) unlike to S-AlA+B. 
The fact that delamination is only visible at the interface of aluminum foils and coating A could be explained by: i) the release of gases during the decomposition of the coating, ii) the dilatation coefficient difference between coating and aluminum foil and iii) the lower adhesion between coating $\mathrm{A}$ and aluminum foil compared to the adhesion between coating $\mathrm{A}$ and sandblasted steel. Indeed, according to i), when the coating is exposed to fire, the coating A softens, and takes a wavy shape (Figure 10 a) and Figure 11) due to the release of some gases [4 - 8]. These gases are trapped between aluminum foil and provoke a delamination. Moreover, to confirm assumption iii), pull-off tests were carried out on S-AlA and S-A to quantify the adhesion difference between aluminum foil/coating A and sandblasted steel/coating A, respectively. These tests reveal that coating A has a significantly stronger adhesion with sandblasted steel than with aluminum foils. For this reason, when coating A is in contact with aluminum foil, delamination occurs when coating A starts to decompose.

On the other hand, delamination occurs earlier on the aluminum foil glued onto steel plate (for $\mathrm{S}-\mathrm{Al} \mathrm{A}+\mathrm{AlB}$ and $\mathrm{S}-\mathrm{Al} \mathrm{A}+\mathrm{B}$ ) compared to the aluminum foil placed between coating $\mathrm{A}$ and $\mathrm{B}$ (for $\mathrm{S}-\mathrm{A}+\mathrm{AlB}$ ). It is assumed that aluminum foils glued onto steel plate are more constrained (and so, they cannot accommodate the stresses) (Figure 10 c)) than aluminum foil between both coatings. Indeed, the delamination of S-A+AlB (Figure $10 \mathrm{~b}$ )) occurs later due to the higher degree of freedom of aluminum (accommodation of stresses is possible), and thus can easily adapt to the deformation and decomposition of coating A compared to aluminum foils glued onto steel plate. To verify this assumption, the fire test of $A l A+B$ without steel plate was carried out to remove the constraint imposed by the substrate. The aim of this test was to reveal if delamination takes place at the same time with and without applied constraint by steel plate. As expected, a delamination was observed for $\mathrm{Al} A+\mathrm{B}$, after 2 min of fire exposure compared to 10 min for $\mathrm{S}-\mathrm{AlA}+\mathrm{B}$, which confirms the previous assumption. Therefore, the constraint applied by the steel plate, and thus the localization of aluminum foil in the system have an influence on the delamination and consequently on the fire protective properties. 
a) $S-A I A+A I B$

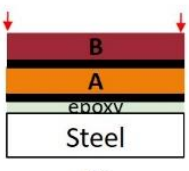

os

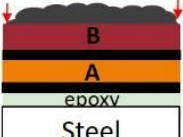

Steel

40s

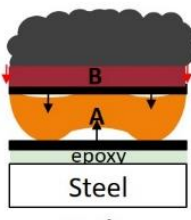

$2 \mathrm{~min}$
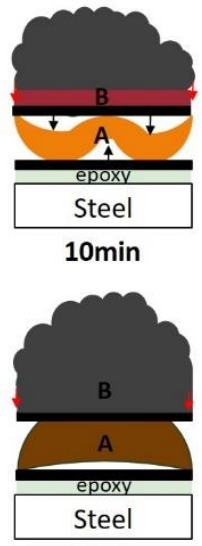

$30 \mathrm{~min}$ b) $S-A+A \mid B$

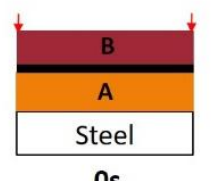

Os

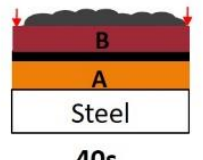

40s

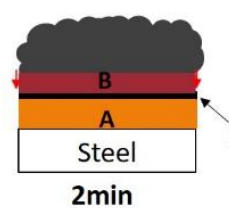

2 min
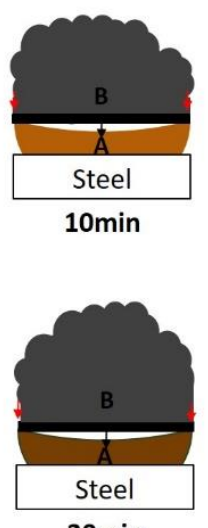

$30 \mathrm{~min}$ c) $\mathrm{S}-\mathrm{Al} \mathrm{A}+\mathrm{B}$
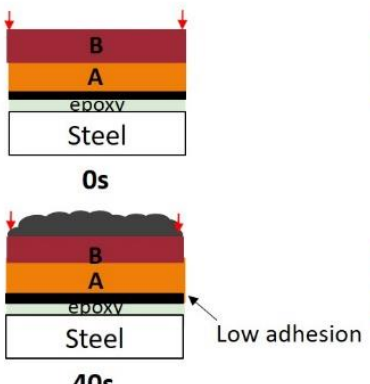

40s

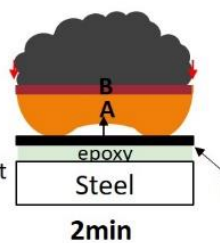

High constrain

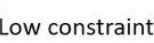

$2 \mathrm{~min}$
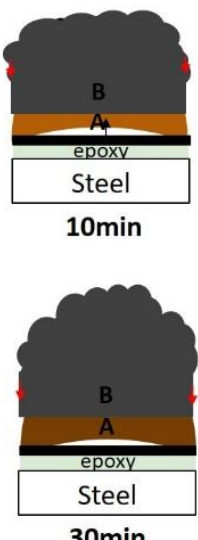

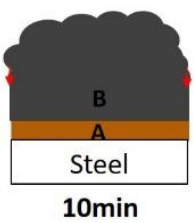

d) $\mathrm{S}-\mathrm{A}+\mathrm{B}$
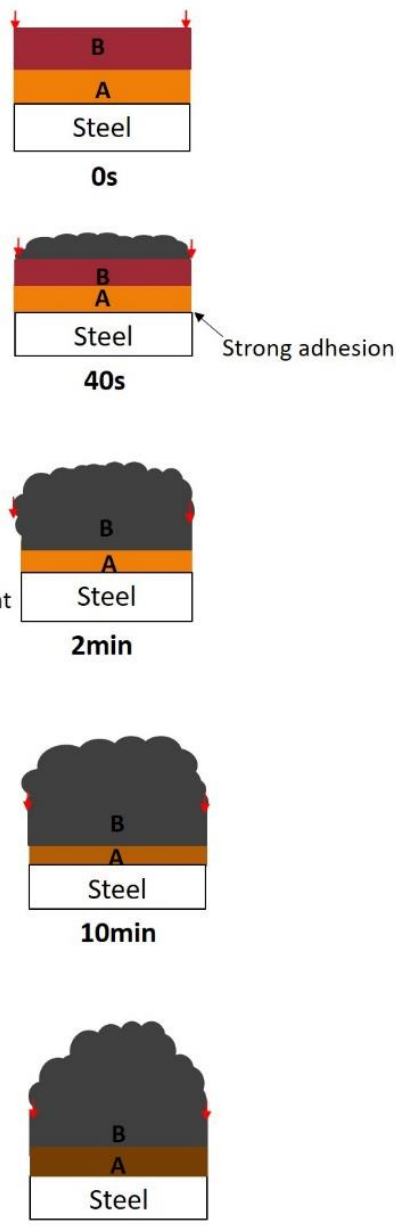

$30 \mathrm{~min}$

Figure 10. Mechanism of protection during the fire test for a) $S-A l A+A l B, b) S-A+A l B, c) S-A l A+B, d)$ $S-A+B$.
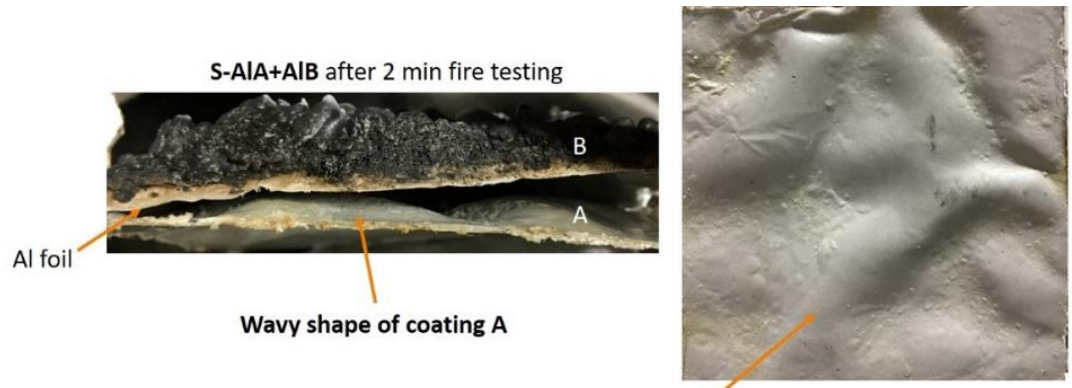

Wavy shape of coating $\mathbf{A}$ after 2 min fire testing

Figure 11. Observation of the wavy shape of coating A after 2 min fire testing 


\section{Conclusions}

In this work, novel designs of fire barriers based on a combination of two different intumescent coatings (A and B) laminated or not using aluminum foils were evaluated in term of fire protection and their mechanism of action were elucidated. With a simple overlay, no improvement in terms of fire protection is achieved. However, with a laminated design inspired from PML, fire protective properties are improved. In particular, a drastic reduction of the temperature at the backside of the protected steel plate is observed at early stage of the fire exposure for all laminated samples, which answers one of the main challenges in the intumescent coating industry. Combining two different intumescent coatings showing different chemistries and expansion behavior with the metal foils is the key innovation of this work. The order of the coatings has to be chosen wisely: depending on their fire behavior, one shows better performances when placed on the top whereas the second one is more effective when placed in between aluminum foils. The best fire performances are obtained with the two aluminum foils design. This configuration allows (i) to drastically decrease the slope of the time-temperature curve up to 20 minutes and (ii) to then reach a plateau barely above the reference up to the end of the test. These excellent fire protective properties are mainly due to two delaminations occurring during fire test. This work highlights that by changing the design of a fire barrier combining different coatings instead of the chemistry of it components, its fire protection properties can be optimized.

\section{Funding}

This work has received funding from the European Research Council (ERC) under the European Union's H2020- the framework programme for Research and Innovation (20142020) ERC Grant Advances Agreement N670747-ERC 2014 AdG/FireBar-Concept for FireBar Concept project.

\section{References}

[1] Alongi, J.; Han, Z.; Bourbigot, S. Intumescence: Tradition versus novelty. A comprehensive review. Prog. Polym. Sci. 2014, 51, 28-73.

[2] Jimenez, M.; Duquesne, S.; Bourbigot, S. High-throughput fire testing for intumescent coatings. Ind. Eng. Chem. Res. 2006, 45, 7475-7481. 
[3] Jimenez, M.; Duquesne, S.; Bourbigot, S. Kinetic analysis of the thermal degradation of an epoxy-based intumescent coating. Polym. Degrad. Stab. 2009, 94, 404-409.

[4] Jimenez, M.; Duquesne, S.; Bourbigot, S. Characterization of the performance of an intumescent fire protective coating. Surf. Coat. Technol. 2006, 201, 979-987.

[5] Jimenez, M.; Duquesne, S.; Bourbigot, S. Multiscale experimental approach for developing high-performance intumescent coatings. Ind. Eng. Chem. Res. 2006, 45, 45004508.

[6] Jimenez, M.; Bellayer, S.; Naik, A.; Bachelet, P.; Duquesne, S.; Bourbigot, S. Topcoats versus Durability of an Intumescent Coating. Ind. Eng. Chem. Res. 2016, 55, 9625-9632.

[7] R. G. Puri and A. S. Khanna, "Intumescent coatings : A review on recent progress," J. Coatings Technol. Res., vol. 14, pp. 1-20, 2016.

[8] T. Mariappan, "Recent developments of intumescent fire protection coatings for structural steel : A review," J. fire, vol. 34 (2), pp. 120-163, 2016.

[9] Müller, B.; Hagenbeek, M.; Sinke, J. Thermal cycling of (heated) fibre metal laminates. Compos. Struct. 2016, 152, 106-116.

[10] Vogelesang, L.B.; Vlot, A. Development of fibre metal laminates for advanced aerospace structures. J. Mater. Process. Technol. 2000, 103, 1-5.

[11] Sinmazçelik, T.; Avcu, E.; Bora, M.Ö.; Çoban, O. A review: Fibre metal laminates, background, bonding types and applied test methods. Mater. Des. 2011, 32, 3671-3685.

[12] Sadighi, M.; Alderliesten, R.C.; Benedictus, R. Impact resistance of fiber-metal laminates: A review. Int. J. Impact Eng. 2012, 49, 77-90.

[13] Timme, S.; Trappe, V.; Korzen, M.; Schartel, B. Fire stability of carbon fiber reinforced polymer shells on the intermediate-scale. Compos. Struct. 2017, 178, 320-329.

[14] W. J. C. Sang Yoon Park, "The Guidelines of Material Design and Process Control on Hybrid Fiber Metal Laminate for Aircraft Structures," in Optimum Composite Structures, 2019, pp. 70-92.

[15] Christke, S.; Gibson, A.G.; Grigoriou, K.; Mouritz, A.P. Multi-layer polymer metal laminates for the fire protection of lightweight structures. Mater. Des. 2016, 97, 349-356.

[16] L. Geoffroy, F. Samyn, M. Jimenez, and S. Bourbigot, "Intumescent Polymer Metal Laminates for Fire Protection," Polymers (Basel)., vol. 10, no. 9, pp. 1-16, 2018.

[17] Tranchard, P.; Samyn, F.; Duquesne, S.; Thomas, M.; Estèbe, B.; Montès, J.-L.; Bourbigot, S. Fire behaviour of carbon fibre epoxy composite for aircraft: Novel test bench and experimental study. J. Fire Sci. 2015, 33, 247-266. 